\title{
THE METABOLIC RESPONSES OF THE COMMON IGUANA, IGUANA IGUANA, TO ACTIVITY UNDER RESTRAINT*
}

\author{
WALTER R. MOBERLY† \\ Department of Zoology, University of Michigan, Ann Arbor, Michigan
}

(Received 20 February 1968)

\begin{abstract}
In the iguana, standard metabolism increased with temperature with a $Q_{10}$ of $2 \cdot 24$. Metabolic scope was greatest at $32^{\circ} \mathrm{C}$, decreasing above and below this temperature. Resting and post-activity heart rates varied with temperature with $Q_{10}$ 's of 2.02 and 1.84 , respectively.

2. Energy produced anaerobically by the production of lactic acid was shown to provide at least three-fourths of the total energy used during activity.

3. Glycogen reserves in the muscle were adequate to account for the production of lactate during activity.

4. The rapidity with which an iguana could remove an accumulated oxygen debt was temperature-dependent, and appeared to be greatest at the temperature where the metabolic scope was greatest.
\end{abstract}

\section{INTRODUCTION}

LIZARDS are a group of poikilothermic vertebrates with considerable behavioral capacity for thermal regulation. During activity they regulate their body temperature with fair precision at levels which are generally rigidly set for a particular species (Bogert, 1949). Recent studies have attempted to relate various physiological parameters to these levels, and a good correlation has been found in many cases (see Dawson, 1967, for a review of this work). However, a fair number of cases exist in which aerobic metabolism of the whole animal and parameters related to aerobic metabolism do not seem to correlate in any obvious manner with the level of body temperature selected.

Until now, emphasis has been placed upon measuring aerobic metabolism in resting lizards, a bias perhaps carried over from work on birds and mammals, which are heavily dependent on high rates of aerobic metabolism. In lizards as in other reptiles, these rates are characteristically low, approximately one-sixth those of mammals of comparable body size and temperature. When lizards become active, the aerobic metabolism increases only four to five times, whereas it may increase up to twenty times in mammals (Bartholomew \& Tucker, 1963; Karpovich, 1965). These reptiles are nevertheless capable of vigorous, if not prolonged,

* Work supported by an NSF Predoctoral Fellowship for 1962-63 and NIH Predoctoral Fellowships for $1963-66$.

This paper is part of a dissertation submitted in partial fulfillment of the requirements for the Ph.D. degree at the University of Michigan.

$\dagger$ Present address: Department of Biology, University of Oregon, Eugene, Oregon. 
activity, and they face the same problems of escape from predators, reproduction, and, to a lesser degree, food gathering as do their homeothermic counterparts. In view of their limited capacities for aerobic metabolism, they must depend heavily on anaerobic pathways, which provide a large source of quick energy for activity that can later be replenished aerobically at a leisurely rate.

Before activity metabolism can be meaningfully evaluated with regard to the adaptation of a poikilotherm to its environment, some point of reference must be established. In lizards this point is the standard metabolism. Standard metabolism can be defined simply as the metabolic rate of a fasting animal resting in the dark while in thermal equilibrium with its environment (Krogh, 1914). Taken as such, it has been measured for a considerable number of lizards (see Dawson, 1967, for a review and discussion of the patterns of standard metabolism as functions of temperature). One can also measure the maximum aerobic metabolism possible during activity for a lizard at varying temperatures. This is then compared with the corresponding values for standard metabolism to give an estimate of the capacity for exercise of the lizard at a given temperature. Increased metabolism due to activity or higher body temperatures demands the distribution of greater volumes of oxygen-rich blood to the tissues. For this reason cardiovascular function, and most especially heart rate, has also been studied under standard and activity conditions in lizards. These data have also been reviewed by Dawson (1967).

Certain properties of the blood chemistry indicate the state of the animal at rest and after activity. It was felt that analysis of the following parameters would yield valuable insights into the physiology of exercise in the iguana. The amount of lactic acid in the blood and tissues before and after exercise was determined, as it indicates the intensity of the anaerobic activity recently undertaken by the animal. The levels of blood glucose were similarly measured, as they are a valuable index of the general vigor and nutritional state of the animal. They may also indicate shifts related to the use of glycogen stores. The actual major sites of glycogen storage were also felt to be important and thus were determined. If the location of the glycogen stores is in the muscles, then the supply of energy during activity would be considerably simplified. If the location is elsewhere, then continuous and effective blood flow from this site to the muscles becomes much more important during activity.

\section{BEHAVIOR AND NATURAL HISTORY}

In order to appreciate properly the physiological adaptations to be discussed in both this and a subsequent paper (Moberly, 1968), certain important features of the animal's behavior and natural history must be considered at this time. For a detailed account, the reader is referred to Moberly (1966). The iguana is a large, tropical, aboreal lizard which grows to a total length of $168 \mathrm{~cm}$ and a weight of $6 \mathrm{~kg}$ (Swanson, 1950). It has a very wide range in the New World, occurring as far north as Sinaloa, Mexico, throughout Central America, and into northern South America (Taylor, 1956). Iguana iguana iguana, the subspecies used in this study, 
occurs in northern South America to the Atlantic Coast of Costa Rica, and on many of the Caribbean Islands.

The animals used in this study all originally came from Colombia, South America. Most were obtained from commercial sources in Florida. All natural history observations were made in Colombia. They commonly occur along rivers and other bodies of water in that country. They are ubiquitous along rivers below $1000 \mathrm{~m}$ in elevation, even occurring where the native riparian habitat has been reduced to a few large trees, which they occupy. Iguanas also occur in the mangrove swamps. In these areas of extremely brackish water, they are only found in trees near those bayous where water remains after the tide has receded.

Iguanas are extremely sedentary creatures both in nature and in the laboratory. Once situated in trees, these lizards will often remain essentially motionless for hours. At some time during the middle of the day they will usually forage briefly, taking advantage of the accessibility of leaves, fruits, flowers and very occasionally carrion (Loftin \& Tyson, 1965). Voluntary activity, then, is extremely limited in both intensity and amount, and probably 90 per cent of the day is spent quietly sitting in one position.

When threatened by predation, the first response of the animal is to "freeze" in a manner that reduces the chance of detection. If detected, the iguana will leap to the ground or into the water under the tree, sometimes falling up to $60 \mathrm{ft}$. In the latter instance, it dives beneath the surface, and that is usually the last seen of it. Swanson (1950) reported that iguanas sometimes will swim a considerable distance under the water from the point of entry and will then hide in the surrounding brush. If the animal hits the ground anywhere near the water, it will run and dive in, disappearing as rapidly as possible. In rare instances where water is not available, the animal, after leaping from the tree, will run to an adjacent tree and scale it.

All periods of activity by iguanas are of extremely short duration, usually lasting less than $30 \mathrm{sec}$ and involving horizontal movements of no more than $50 \mathrm{ft}$. It is unknown how long the animals remain under water in nature, for no animal was ever seen emerging.

Body temperatures were measured for twenty-seven animals that were either shot or captured by chasing them out of their trees at three localities in Colombia: near Cali, an inland city of moderate climate (elevation: about $1000 \mathrm{~m}$ ); the mangrove swamps of the Pacific Coast near Buenaventura; and Tierra Alta, an inland lowland town of the Atlantic coast of Colombia. The distribution of these temperatures appeared to be a normal one about a mean of $33.8^{\circ} \mathrm{C}$, with a range of $26 \cdot 0-40 \cdot 4^{\circ} \mathrm{C}$. The samples from the three localities did not differ significantly. Tierra Alta had both the highest and lowest values, with those from the other localities interspersed with the intermediate values from this place. The animals observed seemed to show little need for elaborate behavioral regulation of body temperature. In the areas visited, it appeared that the lizards could sit in one place in the sun for the entire day and not overheat. McGinnis \& Brown (1966) also noted that in Mexico I. iguana could find a single place to remain for long periods without the need for movements in and out of the sun. This is probably due to the 
large body size and relatively cool temperatures surrounding them in the trees. Also, in Colombia, the amount of insolation at the time of the study was quite moderate, due to the presence of a light cloud cover and high humidity at most times.

Hirth (1963) reported that the body temperatures of adult iguanas living along a tropical strand in Costa Rica averaged $36 \cdot 1^{\circ} \mathrm{C}\left(34 \cdot 0-37 \cdot 2^{\circ} \mathrm{C}\right)$. McGinnis \& Brown (1966) reported that the mean body temperature of iguanas in the field in Mexico was $36 \cdot 2^{\circ} \mathrm{C}$. The difference between the means of these two investigators and the present author seems to be very real, for only four of the twenty-seven Colombian iguanas had body temperatures of $36^{\circ} \mathrm{C}$ or higher. Since the mean air temperature in Colombia $\left(28.5^{\circ} \mathrm{C}\right)$ was only slightly below those for Costa Rica $\left(29.6^{\circ} \mathrm{C}\right)$ and Mexico $\left(32.1^{\circ} \mathrm{C}\right)$, perhaps the discrepancies between the means for the animals from these localities may be due to more intense insolation occurring in Costa Rica and Mexico at the time of these studies. The observations in Colombia were made in the rainy season, except at Cali. The closeness of the results of McGinnis \& Brown (1966) and of Hirth (1963) lead me to believe that $36.2^{\circ} \mathrm{C}$ is the preferred temperature of 1 . iguana in the field. Perhaps the animals in Colombia simply cannot attain such body temperatures during some times of the year.

\section{MATERIALS AND METHODS}

Iguanas ranging in weight from 369 to $1220 \mathrm{~g}$ were kept in a large room on a daily photoperiod of $12 \mathrm{hr}$. Room temperature usually varied from about $22^{\circ}$ to $30^{\circ} \mathrm{C}$. Heat lamps and large branches were available to the iguanas for basking. These animals were fed a diet of leaf lettuce, bananas and canned dog food, and most maintained themselves in excellent condition. Sul-Met, a liquid sulfa drug, was added to the water to reduce the possibility of mouth infection. This did not appear to affect the metabolism of the animal, as fresh animals which had not taken the drug showed no apparant physiological differences from those which had.

The lizards were taken from the cage on the afternoon preceding the experimental run. They were tied on a raised plywood platform, so that the body was immobile but the legs were unrestrained, and then a neoprene gasket was glued over the neck and under the jaw using Carter's Contact Cement. When the gasket had set, a neoprene mask was glued to it, covering the eyes, mouth and nostrils. The mask contained an air inlet and outlet for the lizard, but otherwise was completely air- and light-tight. Electrocardiograph (EKG) leads were attached subdermally by gold-plated safety pins to the front legs, and a ground lead was attached to the tail. A thermocouple of 30 gauge copper-constantan wire was inserted at least $6 \mathrm{~cm}$ into the animal's cloaca. The iguana was then placed in a constant-temperature cabinet that remained within $\pm 0 \cdot 2^{\circ} \mathrm{C}$ of the desired level. An illustration of an iguana rigged in the above fashion may be seen in the paper by Tucker (1966).

A constant known flow of air, between 250 and $600 \mathrm{ml} / \mathrm{min}$, was run into the mask, over the head of the animal, out to a train of Drierite and Ascarite (water vapor and $\mathrm{CO}_{2}$ absorbants, respectively) and then through a Beckman G-2 Oxygen Analyzer. These components were connected by Tygon tubing. With this arrangement it was possible to monitor oxygen consumption continuously. EKG's and body temperatures could also be registered continuously using a Sanborn recording oscillograph and a Honeywell recording potentiometer, respectively.

In those cases in which changes in blood chemistry were to be measured, an indwelling cannula was placed in the systemic arch. Animals were anesthetized with an intraperitoneal 
injection of $300-500 \mathrm{mg} / \mathrm{kg}$ tricaine (MS 222-Sandoz) and a 3-cm incision was made in the ventral side of the neck, ending just anterior to the pectoral girdle. The hyomandibular artery was cannulated with PE50 polyethylene tubing filled with heparinized saline, and the tip of the cannula was positioned to lie in the systemic arch. The cannula was exteriorized by forcing a hypodermic needle down from the dorsal side of the neck to the incision, and then threading the cannula through to the dorsal side. The wound was sutured and glued together with methyl-2-cyanoacrylate monomer. All animals used completely recovered from the anesthesia in 30-60 min with no apparent side-effects. This procedure left a lizard with a cannula that could easily be reached for sampling mixed arterial blood at any time. The lizard was not initially heparinized. The cannula stayed open without clotting for up to 6 days, even though the amount of heparinized saline entering the blood was kept to a minimum.

Prior to measurement of standard metabolism, the body temperature of the iguana was adjusted to a desired level between $14^{\circ}$ and $42^{\circ} \mathrm{C}$ and the animal allowed to remain in a resting condition for at least $2 \mathrm{hr}$. At the end of this period, standard metabolism was determined by averaging at least ten consecutive points during the half-hour of the run in which oxygen consumption was minimal. This procedure was necessitated by the small volume of the mask. This was so small that single exhalations would pass through the analyzer with less mixing than would be obtained in a larger container. This loss of mixing in the system caused the analyser to give considerably more erratic values than are normally recorded, necessitating the averaging procedure. At some time when the rate of oxygen consumption was near the minimum level obtained for a particular temperature, heart rate was measured.

Maximum rates of oxygen consumption possible were determined by stimulating the lizards to struggle violently on the jig. This was accomplished by first manually disturbing them. When they began to become refractory to this treatment, they were given mild faradic stimulation via the EKG leads. Animals were stimulated in this fashion until they would no longer respond, usually after a period of 2-3 $\mathrm{min}$. Oxygen consumption was monitored continuously during this process, and a value for the maximum rate of aerobic metabolism was obtained by averaging the values over the 10 min period in which oxygen consumption was greatest. Maximum heart rate was obtained from values measured during and immediately after stimulation.

Blood lactate and glucose were determined for some of the animals just before stimulation and at selected intervals during the subsequent $3 \mathrm{hr}$ by extracting $100-\mu 1$ samples from the cannula using a modified Warburg calibrator and disposable pipettes. These samples were then deproteinized, centrifuged and the supernatant decanted for analysis. Both lactic acid and blood glucose were determined using the enzymatic test reagents provided commercially by Biochemica Boehringer. The lactic acid test method uses the modified enzymatic determination of Scholz et al. (1959), based on the conversion of NAD to NADH as lactate is converted to pyruvate by lactic dehydrogenase. Using a Beckman DB spectrophotometer, at $340 \mathrm{~m} \mu$ under the conditions of the test, a difference in absorbance of 0.100 corresponds to $0.0161 \mu \mathrm{m}$ of NADH per $\mathrm{ml}$ in the cuvette. Lithium lactate standards were used in each test and were treated exactly as the blood samples. Duplicate blood samples agreed within 2 per cent. All determinations reported for lactate are the means of these duplicate samples. Blood glucose was determined using the enzymatic method of Huggett $\&$ Nixon (1957), in which glucose, oxygen, $o$-dianisidine, glucose oxidase and peroxidase yield gluconic acid, water and oxidized $o$-dianisidine. Oxidized o-dianisidine is brown, and the quantitative production of this dye was measured on a Coleman colorimeter at $436 \mathrm{~m} \mu$. Glucose standard and control tubes were treated exactly alike and run with the duplicate blood samples. Duplicate determinations agreed within 4 per cent, and all values reported are the means of the two determinations.

The normal resting glycogen levels of liver and muscle were determined for six iguanas ranging in weight from 369 to $455 \mathrm{~g}$. All animals were used within 1 day of capture in 
Colombia. They were kept in heavy cloth sacks in a darkened room at about $25^{\circ} \mathrm{C}$ and showed few signs of activity. At the time of measurement the lizards were quickly removed from their bag and decapitated. Duplicate muscle (trapezius and pubioischiotibialis) and liver samples were taken within $1 \mathrm{~min}$, dropped into $\mathrm{KOH}$ in a weighed test tube, weighed and then placed in their tubes in boiling water. Glycogen was determined according to the colorimetric method of Seifter et al. (1950), using anthrone. This method would also detect the free glucose in the tissue, but this is probably in such small amounts when the animal is at rest that the error would be negligible. Arterial blood samples were also taken at the time of death and later analyzed for lactic acid concentration as described above.

\section{RESULTS}

Oxygen consumption and heart rate

The results obtained for the measurement of oxygen consumption for fifteen iguanas tested over the range of temperature $14-42^{\circ} \mathrm{C}$ are shown in Fig. 1. When

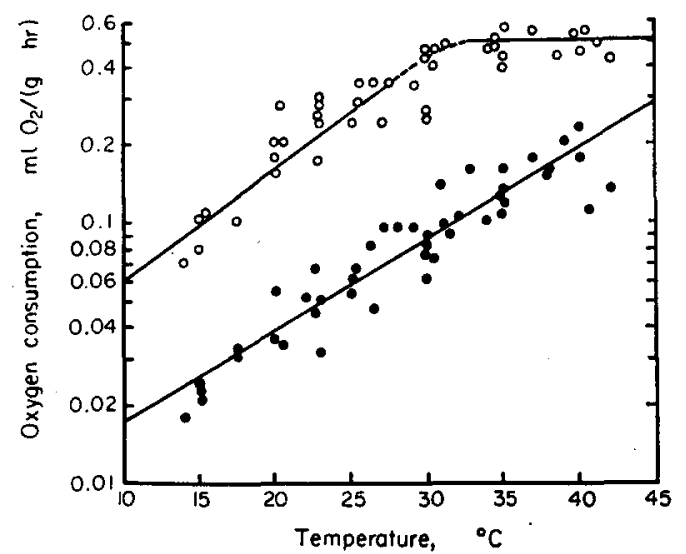

Fig. 1. Oxygen consumption as a function of temperature in $I$. iguana. The shaded circles and the unshaded circles represent standard values and maximum levels of oxygen consumption with activity, respectively. The solid lines are the least-squares regressions fitted to the data.

plotted semilogarithmically, the values for standard metabolism can be described by a straight line fitted by the method of least squares. This line has the formula:

$$
\text { Log met. }\left(\mathrm{ml} \mathrm{O}_{2} \mathrm{~g}^{-1} \mathrm{hr}^{-1}\right)=0.899+0.034 T_{b} \text {, }
$$

where $T_{b}$ is the body temperature in degrees centrigrade. The slope corresponds to a $Q_{10}$ of $2 \cdot 24$. The data may deviate slightly from this relationship between $14^{\circ}$ and $20^{\circ} \mathrm{C}$, where the $Q_{10}$ appears to be more than $2 \cdot 24$, but this is not important in the context of the study. The data for maximum metabolism bear quite a different relation to temperature. In this case metabolism rises steadily until about $30^{\circ} \mathrm{C}$, above which it levels off. When the least-squares method is applied to the points between $14^{\circ}$ and $27 \cdot 5^{\circ} \mathrm{C}$, a line with the formula

$$
\text { Log Met. }\left(\mathrm{ml} \mathrm{O}_{2} \mathrm{~g}^{-1} \mathrm{hr}^{-1}\right)=0.481+0.037 \mathrm{~T}_{\mathrm{b}}\left({ }^{\circ} \mathrm{C}\right)
$$


is obtained. In this case the slope corresponds to a $Q_{10}$ of 2.68. The least-squares regression between $32.5^{\circ}$ and $42^{\circ} \mathrm{C}$ yields a $Q_{10}$ of 1.02 , and the line has the formula:

$$
\text { Log met. }\left(\mathrm{ml} \mathrm{O}_{2} \mathrm{~g}^{-1} \mathrm{hr}^{-1}\right)=1.663+0.001 T_{b}\left({ }^{\circ} \mathrm{C}\right) \text {. }
$$

The two lines thus generated would meet at about $32^{\circ} \mathrm{C}$. However, the relationship is almost certainly curvilinear in the vicinity of this temperature.

The results for the measurement of heart rates in sixteen iguanas for the range of temperature $15-42^{\circ} \mathrm{C}$ is shown in Fig. 2. Most of these rates were measured

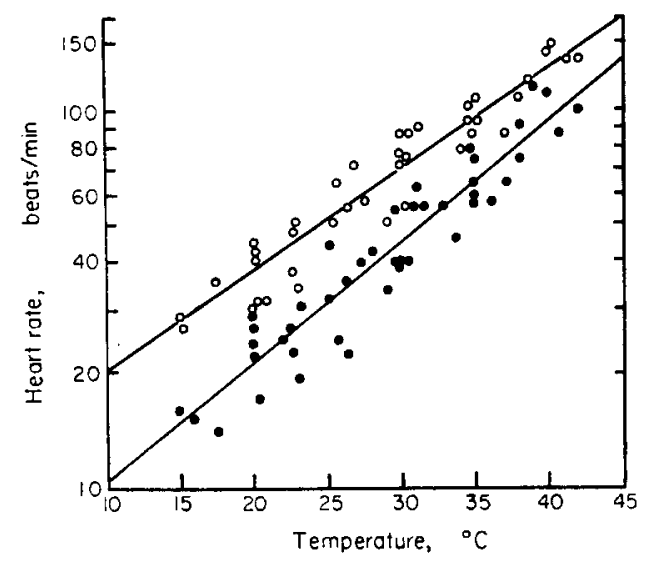

FIG. 2. Heart rate as a function of temperature in I. iguana. The shaded circles and the unshaded circles represent resting levels and maximal values immediately after exercise, respectively. The lines are the least-squares regressions fitted to the data.

simultaneously with the determinations of oxygen consumption shown in Fig. 1. Resting heart rate (H.R.) is seen to increase linearly when plotted semilogarithmically. The formula for the straight line obtained by least-squares regression is

$$
\text { Log H.R. (beats } / \mathrm{min})=0.687+0.032 T_{b}\left({ }^{\circ} \mathrm{C}\right) \text {. }
$$

The slope of this line corresponds to a $Q_{10}$ of 2.02. Maximum heart rate can also be described by one straight line when plotted in the above fashion. The leastsquares regression yields the formula:

$$
\text { Log H.R. (beats } / \mathrm{min})=1 \cdot 022+0 \cdot 027 T_{b}\left({ }^{\circ} \mathrm{C}\right) \text {. }
$$

The slope of this line corresponds to a $Q_{10}$ of 1.84 . Considerably more variation is evident in the data for heart rate than those for oxygen consumption in the iguana.

Electrocardiograms were taken from the leads described above for heart rate. Wave forms corresponding to the $P, R, S$ and $T$ waves of the mammalian electrocardiograph were always present, and the $Q$ wave was occasionally seen. The duration of the $P-R, S-T$ and $P_{\tau}-T_{f}$ intervals as defined by Dawe \& Morrison (1953) were measured in ten iguanas during rest and exercise over the range of 
temperature $15-40^{\circ} \mathrm{C}$. The $P-R$ interval was measured from the peak of the $P$ wave to the peak of the $R$ wave, which gives a good estimate of the auriculoventricular $(A V)$ conduction time without the necessity of determining the exact beginning of the $P$ and $R$ waves. These were sometimes hard to find. The $S-T$ interval was measured from the peak of the $S$ wave to the peak of the $T$ wave. It provides a reliable and easily measured portion of the time required for cardiac repolarization. The $P_{i}-T_{f}$ interval was measured from the beginning of the $P$ wave to the end of the $T$ wave, but could not be determined for all records. These same intervals have been used for other lizards by Dawson (1960) and Dawson \& Templeton (1963).

The data for interval duration as a function of temperature in I. iguana are shown in Fig. 3. As would be anticipated, all of the durations measured are

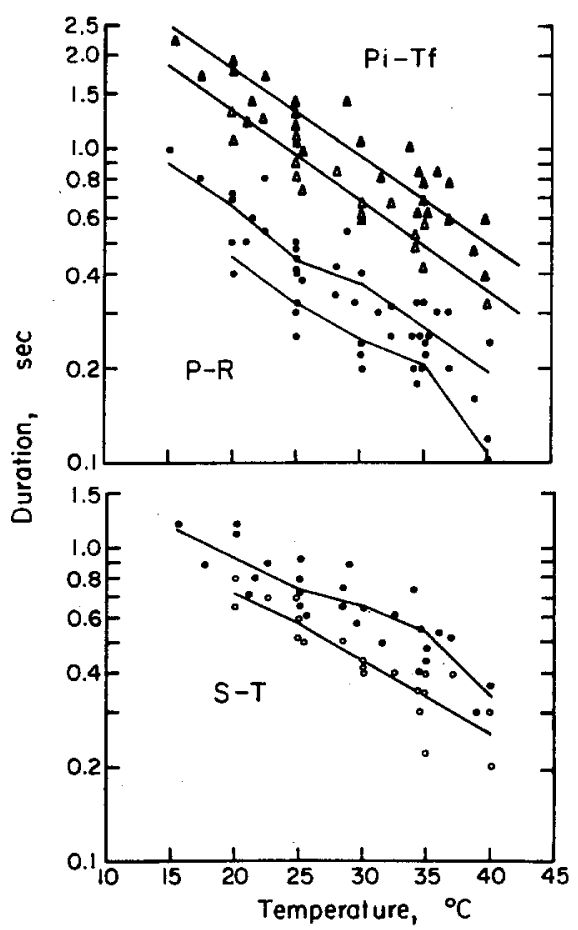

FIG. 3. Duration of electrocardiograph intervals as functions of temperature in I. iguana. In each case the shaded symbols represent resting values, and the unshaded symbols maximum values after exercise. The solid lines drawn through the $P_{i}-T_{f}$ points are the least-squares regressions for these data. The other lines pass through the means for data within successive $5^{\circ} \mathrm{C}$ intervals.

inversely related to temperature. The $P-R$ intervals appear to bear an exponential relation to temperature over at least part of the range and are in every case shorter than the corresponding $S-T$ intervals, as in the other lizards studied to date (Dawson, 1960; Dawson \& Templeton, 1963). Plotted semilogarithmically, $P-R$ 
duration at rest appears to be linear over the entire range of temperature studied, and the reciprocal of the intervals yields a $Q_{10}$ of $2 \cdot 0 . P-R$ duration after exercise shortens to 55-75 per cent of the resting values. The reciprocal of the intervals for the straight-line portion from $20^{\circ}$ to $35^{\circ} \mathrm{C}$ yields a $Q_{10}$ of $1 \cdot 7$. Above $35^{\circ} \mathrm{C}$, the $P-R$ duration after exercise seems to shorten drastically, with the $Q_{10}$ for the reciprocal being $3 \cdot 7$. However, this is based on a very limited number of points and should be regarded as a tentative estimate.

Between $15^{\circ}$ and $35^{\circ} \mathrm{C}, S-T$ duration at rest falls linearly on a semilogarithmic grid, with the $Q_{10}$ for the reciprocal of the durations approximating $1 \cdot 5$. The duration of this interval declines more rapidly from $35-40^{\circ} \mathrm{C}$, with the $Q_{10}$ for the reciprocal being $2 \cdot 7 . S-T$ duration after exercise declines exponentially over the entire range of temperature studied with a $Q_{10}$ for the reciprocal of $1 \cdot 7$. When plotted on a semilogarithmic grid, $P_{i}-T_{f}$ durations for both resting and active animals fall linearly with increasing temperature over the entire range studied. The $Q_{10}$ reciprocal is 1.9 in both cases.

\section{Lactic acid in the blood}

When animals were stimulated to maximum activity on the jig, blood lactic acid concentrations rose rapidly at all temperatures. The final concentrations reached were usually above $100 \mathrm{mg}$ per cent, but were always below $160 \mathrm{mg}$ per cent, and averaged $116 \mathrm{mg}$ per cent at all of the temperatures tested. A similar independence of temperature has been noted for lactate concentrations in active fish (Black, 1957).

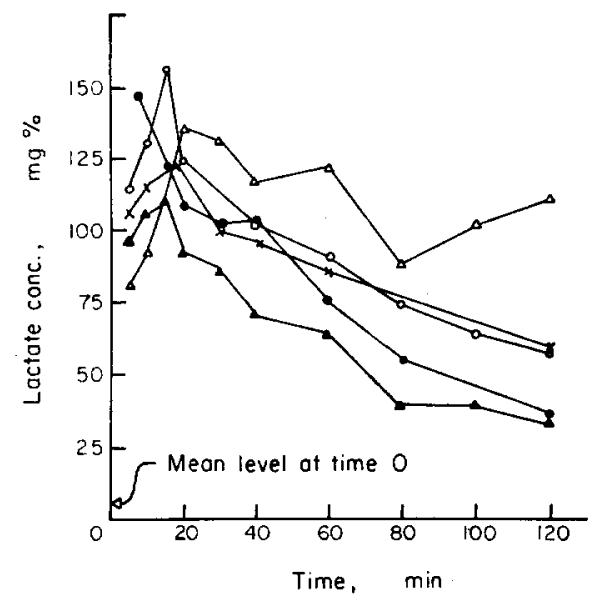

Fig. 4. A typical accumulation and removal of lactic acid from the blood of an iguana after exercise at different body temperatures.

Although the final lactate concentration reached in iguanas was essentially the same at all temperatures, the rate at which this oxygen debt was eliminated showed a strong thermal dependence. A typical case is shown in Fig. 4. As temperature increases, so does the rate at which the debt is removed up to $35^{\circ} \mathrm{C}$. At $40^{\circ} \mathrm{C}$ the 
rate appears to be slightly less than that at $35^{\circ} \mathrm{C}$. Plotting the data semilogarithmically yields a straight line, indicating the exponential character of the relation between removal and time. This transformation facilitates determination of the slopes of the lines shown in Fig. 4.

The data gathered for the five lizards tested in each case always conformed to the general relationship to temperature described above. However, considerable variation was apparent, so much in fact that it was not possible to present data for all of the animals in a single graph. Table 1 gives the ranges of the slopes of the

TABLE 1-SLOPES OF THE LINES GENERATED BY PLOTTING THE LOG OF LACTATB CONCENTRATION AS A FUNCTION OF TIME

\begin{tabular}{ccc}
\hline $\begin{array}{c}T_{b} \\
\left({ }^{\circ} \mathrm{C}\right)\end{array}$ & $\begin{array}{c}\text { Range of slopes } \\
{[\log \text { lact. conc. }(\mathrm{mg} \%) / \mathrm{min}]}\end{array}$ & $\begin{array}{c}\text { Slope for all data } \\
\text { [log lact. conc. }(\mathrm{mg} \%) / \mathrm{min}]\end{array}$ \\
\hline 20 & -0.0013 to -0.0026 & -0.0019 \\
25 & -0.0025 to -0.0066 & -0.0054 \\
30 & -0.0054 to -0.0076 & -0.0063 \\
35 & -0.0052 to -0.0084 & -0.0079 \\
40 & -0.0041 to -0.0062 & -0.0050 \\
\hline
\end{tabular}

lines for recovery of the lizards at different temperatures, as well as the slopes of the lines fitted to all of the data. The latter are also shown plotted in Fig. 5. In this case the data have been converted into percentages of the maximum concentration of lactate reached in the blood of the particular individual, in an attempt to reduce some of the variation.

\section{Lactic acid in other tissues}

Lactic acid levels were measured in two other tissues of the body, in an attempt to construct a balance sheet for the total body metabolism during a violent burst of activity. Muscle and liver lactate concentrations were measured immediately after six iguanas were exercised. These animals were stimulated as before until they became almost totally refractory. However, they did not become so thoroughly exhausted as those masked lizards on the jig, because they did not struggle so violently with their eyes not covered. The six animals tested had mean blood lactic acid levels of $84 \mathrm{mg}$ per cent (range: $72-95 \mathrm{mg}$ per cent). The mean levels of lactic acid in the muscle and liver were $246 \mathrm{mg}$ per cent (range: $226-270 \mathrm{mg}$ per cent) and $50 \mathrm{mg}$ per cent (range: $33-61 \mathrm{mg}$ per cent), respectively.

\section{Blood glucose}

Values for blood glucose concentrations varied from 44 to $111 \mathrm{mg}$ per cent, with a mean value of $70 \mathrm{mg}$ per cent for all of the resting individuals studied. Six of these were iguanas that had been in captivity less than a day in Colombia, and their mean was $78 \mathrm{mg}$ per cent (range: 52-111 mg per cent). The other five were the same animals used in the blood lactate study in the preceding section. They had a 
mean of $64 \mathrm{mg}$ per cent (range: 44-90 $\mathrm{mg}$ per cent). The difference between the two means is not regarded as reflecting anything more than the fact that the laboratory animals were at least $24 \mathrm{hr}$ postabsorptive, whereas the individuals from the field might well have eaten a large meal just before capture.

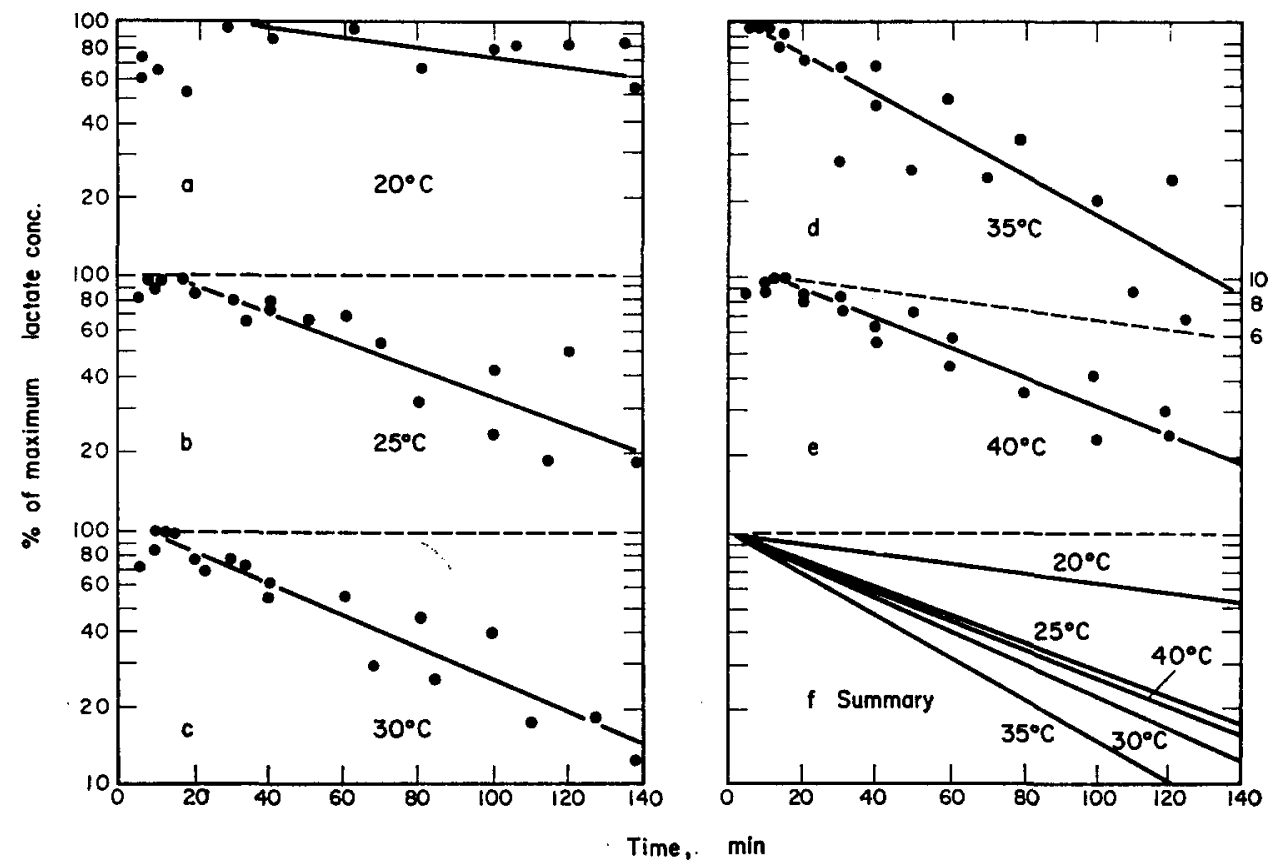

Fig. 5. Removal of lactic acid at various temperatures. The lactate concentrations for five iguanas at five temperatures are plotted as percentages of the respective maximum concentration reached after activity. In graphs a-e the lines drawn are the least-squares regressions for the data points after and including the 100 per cent points. The preceding points are not used for the regression. Graph $f$ is a summary of the regressions obtained in a-e, with time 0 equal to the point where the regressions crossed 100 per cent.

Blood glucose values usually did not change after exercise. However, they dropped steadily in the animal with the highest resting level of blood glucose. The drop may have been due to factors other than exercise. In three other cases, the blood glucose first dropped below the resting value, and then rose above it at the end of the test.

\section{Glycogen determinations}

The liver samples yielded a mean glycogen concentration of $8.01 \mu \mathrm{g} / \mathrm{mg}$ tissue (range: $5.91-10.58 \mu \mathrm{g} / \mathrm{mg}$ ). The shoulder muscle (trapezius) and leg muscle (pubioischiotibialis) were not significantly different from each other, with values of $3.19 \mu \mathrm{g} / \mathrm{mg}$ tissue (range: $0.62-8.55 \mu \mathrm{g} / \mathrm{mg}$ ) and $4.18 \mu \mathrm{g} / \mathrm{mg}$ tissue (range: $0.78-$ $7.21 \mu \mathrm{g} / \mathrm{mg}$ ), respectively. The overall average for both types of muscle was 
$3.69 \mu \mathrm{g} / \mathrm{mg}$ tissue. Blood lactate values had a mean of $4.05 \mathrm{mg}$ per cent (range: 2.66-7.43 mg per cent). These very low values indicate that the animals did essentially no struggling before death and suggest that the measurements were taken from truly resting animals.

\section{DISCUSSION}

\section{Standard and activity metabolism}

Dawson (1967) has reviewed the current status of our knowledge of the physiological adaptations of lizards to their environment. With regard to standard metabolism and resting heart rate he noted two patterns. Among most thermophilic species standard metabolism shows constantly decreasing $Q_{10}$ 's as temperature increases. The $Q_{10}$ 's for resting heart rate in thermophilic forms show an abrupt increase at temperatures above $20^{\circ} \mathrm{C}$. In less thermophilic species the $Q_{10}$ for standard metabolism remains constant over the physiological range, and the $Q_{10}$ for resting heart rate shows an abrupt increase below $10^{\circ} \mathrm{C}$. The patterns of these physiological parameters for the iguana are of the less thermophilic type, but there is no evidence that body temperatures as high as $42^{\circ} \mathrm{C}$ are harmful in any way. McGinnis \& Brown (1966) report that the upper lethal temperature is at $47^{\circ} \mathrm{C}$. Thus the animal could probably best be classed as moderately thermophilic.

When stimulated to activity, iguanas increased their oxygen consumption from four to five times at temperatures between $14^{\circ}$ and $30^{\circ} \mathrm{C}$. This factor declines above $32^{\circ} \mathrm{C}$, so at $40^{\circ} \mathrm{C}$ metabolism is only doubled. It is interesting to note that the maximum oxygen consumption attained is still less than that of a fasting mammal of similar size at rest in its zone of thermoneutrality (basal metabolic rate). Fry (1947) pointed out that the capacity which is most important to an animal is that for becoming active, and that this varies in poikilotherms with the body temperature. He reasoned that if standard metabolism represents the energy required for maintenance of the integrity of the organism, then that available for activity is the absolute difference between maximum and standard metabolism. This difference he called the "metabolic scope". The above will be true only if the organism does not temporarily abandon some maintenance process while undertaking musculature activity, and if it does not use anaerobic metabolism to any extent during this activity. Fry further noted that the point at which the metabolic scope is greatest should logically correspond with the preferred or activity temperature of the species being investigated. This has been demonstrated to be the case for a variety of fishes (Fry, 1947, 1957). It is shown in Fig. 6 that the maximum metabolic scope for the iguana occurs at about $32^{\circ} \mathrm{C}$, which is quite close to the mean of $33.8^{\circ} \mathrm{C}$ observed for animals in the field in Colombia. It decreases on either side of $32^{\circ} \mathrm{C}$, and thus is 16 per cent lower at $36.2^{\circ} \mathrm{C}$, the apparent preferred field temperature (see Behavior and Natural History section, p. 2).

\section{Heart rate and oxygen pulse.}

Licht (1965) has attempted to use heart rate as an indicator of metabolic scope. He reasoned that as oxygen consumption increases, cardiac output would also 
have to rise if oxygen is to be supplied to the tissues in adequate amounts. Thus, he felt that the increment between standard and maximum heart rate should be proportional to metabolic scope. It is, therefore, of interest that he found that the greatest difference between resting and maximum heart rates occurred at body

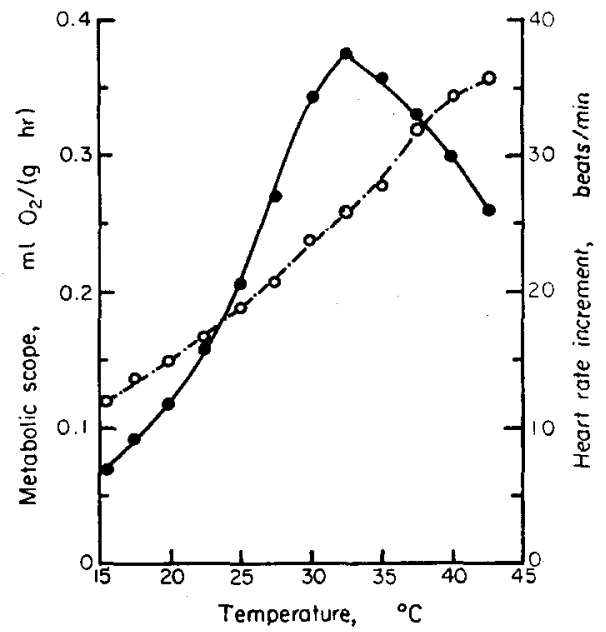

Fig. 6. Temperature dependence of metabolic scope and increment of heart rate in I. iguana. The solid line and shaded circles are metabolic scope, and the dashed line and unshaded circles are the heart rate increment between resting and maximum levels at the particular temperature.

temperatures approximating the preferred temperature in each of four lizards that differed markedly in their temperature relations. A similar correlation between the temperature at which the greatest increment developed and the thermal preferendum was later found for three species of Australian lizards by Dawson, Shoemaker \& Sicht (unpublished data). It should be noted that direct experimental confirmation of the proportionality between the maximum increment of heart rate and metabolic scope is lacking. In fact, all the studies in which both of these functions have been measured indicate little correlation between them (Bartholomew \& Tucker, 1963, 1964; Bartholomew et al., 1965). In the iguana the difference between resting and maximum heart rate increases over the entire range of temperature studied, whereas metabolic scope shows a definite peak at about $32^{\circ} \mathrm{C}$. Thus the increment of heart rate in this animal likewise lacks proportionality to metabolic scope.

In the lizard oxygen consumption must represent the product of heart rate, stroke volume and the arteriovenous difference in the oxygen content of the blood. Consequently an increase in oxygen consumption can involve other physiological adjustments in addition to increasing heart rate (see Tucker, 1966, for a detailed analysis for the iguana). The maximum heart rate increment would be a good indicator of metabolic scope over a range of body temperatures only if the percentage contribution of the increased heart rate to increased oxygen consumption 
remained constant. One way to determine whether or not this is the case is by analysis of the oxygen pulse, the oxygen consumed per heart beat. The values for oxygen pulse in the iguana during standard and maximum metabolism are shown in Fig. 7. The heavy lines drawn through the points represent the values expected

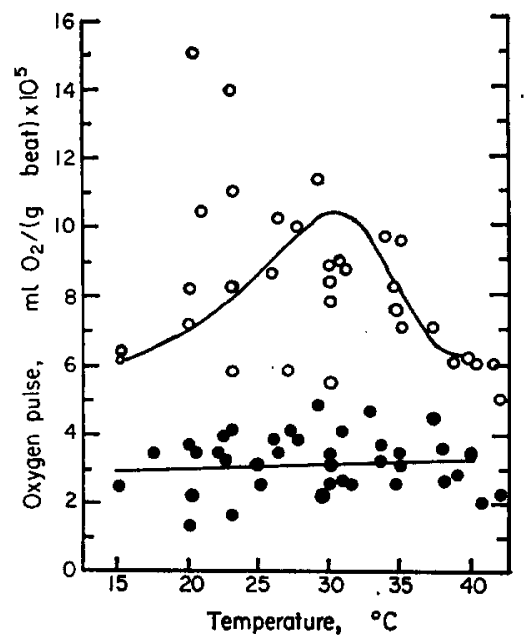

Fig. 7. Oxygen pulse as a function of body temperature in $I$. iguana. Shaded circles and unshaded circles represent standard values and maximum values after exercise, respectively. The lines describe theoretical values obtained from the regressions in Figs. 1 and 2.

for a lizard whose heart rate and oxygen consumption fall along the regression lines shown in Figs. 1 and 2 for that temperature. Oxygen pulse in resting iguanas remains almost constant over the range of temperature studied. However, with maximum activity it shows a complex curve, with maximum values for the oxygen pulse at about $30^{\circ} \mathrm{C}$, and with the values falling off on either side of this point. The considerable scatter apparent in the actual values for oxygen pulse is attributed to the fairly large scatter in the heart rates at low temperatures. The fact that oxygen pulse rises with activity indicates that augmentation of heart rate alone cannot provide the additional oxygen required by the tissues at this time.

With information on the heart rate (HR) and oxygen pulse (OP), it is possible to use the formulation of Bartholomew \& Tucker (1963) for determining the relative contribution of increased heart rate to increased oxygen consumption. The results are tabulated in Table 2. They indicate that augmentation of heart rate never accounts for more than half of the increased requirements for oxygen, and also that the percentage contribution varies drastically with temperature. The remainder of the requirement for oxygen must be met by increased extraction of this gas from the blood (increased arteriovenous difference) and/or stroke volume. Tucker (1966) reported that the A-V difference always increased in iguanas after activity, and that the stroke volume increased in some individuals, but not in all. 
Thus, it would appear that heart rate can be used as an indicator of metabolic scope only in special circumstances.

When analyzing the time relations of the electrocardial events as a function of temperature, the small amount of variation in the slopes of these relations is

TABLE 2-OXYGEN PULSE IN $I$. iguana

\begin{tabular}{|c|c|c|c|}
\hline \multirow{2}{*}{$\begin{array}{c}T_{b} \\
\left({ }^{\circ} \mathrm{C}\right)\end{array}$} & \multicolumn{2}{|c|}{ Oxygen pulse $\left(\mathrm{ml} \mathrm{O}_{2}\right.$ beat $\left.^{-1} \mathrm{~g}^{-1}\right)$} & \multirow{2}{*}{$\begin{array}{c}\text { Contribution of } \\
\text { heart rate to } \\
\text { increased } \mathrm{O}_{2} \\
\text { transport* } \\
(\%)\end{array}$} \\
\hline & Standard & Maximum & \\
\hline $\begin{array}{l}15 \\
20 \\
25 \\
30 \\
35 \\
40\end{array}$ & $\begin{array}{l}3.00 \times 10^{-5} \\
3.05 \times 10^{-5} \\
3.10 \times 10^{-5} \\
3.15 \times 10^{-5} \\
3.20 \times 10^{-5} \\
3.25 \times 10^{-5}\end{array}$ & $\begin{array}{r}6.00 \times 10^{-5} \\
6.92 \times 10^{-5} \\
8.53 \times 10^{-5} \\
10.38 \times 10^{-6} \\
8.44 \times 10^{-5} \\
6.05 \times 10^{-5}\end{array}$ & $\begin{array}{l}40 \cdot 7 \\
34 \cdot 9 \\
25 \cdot 7 \\
18 \cdot 3 \\
22 \cdot 3 \\
28 \cdot 9\end{array}$ \\
\hline
\end{tabular}

* See text for explanation.

notable. During both rest and activity, the $S-T$ and $P-R$ intervals comprise 60-65 and 30-40 per cent of the duration of the $P_{\tau}-T_{f}$ interval, respectively, at all temperatures (Table 3). This indicates that the increase of heart rate during exercise

TABl. 3-EFfects of temperature on the DURation of this $P-R, S-T$ and $P_{r}-T_{1}$ BLBCTROCARDIOGRAPHIC INTERVALS FOR IGUANAS AT REST AND AFTER FXKRRCIBE

\begin{tabular}{cccccc}
\hline $\begin{array}{c}T_{b} \\
\left({ }^{\circ} \mathrm{C}\right)\end{array}$ & $\begin{array}{c}\text { Duration of } \\
P-R(\mathrm{sec})\end{array}$ & $\begin{array}{c}\% \text { of } \\
P_{r}-T_{f}\end{array}$ & $\begin{array}{c}\text { Duration of } \\
S-T \text { (sec) }\end{array}$ & $\begin{array}{c}\% \text { of } \\
P_{r} T_{f}\end{array}$ & $\begin{array}{c}\text { Duration of } \\
P_{r}-T_{f}(\mathrm{sec})\end{array}$ \\
\hline 15 R* & 0.90 & 40 & 1.30 & 58 & 2.25 \\
20 R & 0.66 & 40 & 0.95 & 58 & 1.65 \\
20 X* & 0.46 & 37 & 0.71 & 58 & 1.23 \\
$25 \mathrm{R}$ & 0.44 & 36 & 0.75 & 60 & 1.24 \\
25 X & 0.33 & 35 & 0.58 & 62 & 0.94 \\
30 R & 0.38 & 36 & 0.65 & 61 & 1.06 \\
30 X & 0.25 & 35 & 0.43 & 61 & 0.71 \\
35 R & 0.28 & 34 & 0.53 & 64 & 0.83 \\
35 X & 0.21 & 36 & 0.34 & 59 & 0.58 \\
40 R & 0.20 & 37 & 0.33 & 61 & 0.54 \\
40 X & 0.11 & 31 & 0.24 & 67 & 0.36 \\
\hline
\end{tabular}

* $\mathrm{R}=$ resting conditions; $\mathrm{X}=$ immediately after exercise.

involves acceleration of $A-V$ conduction and cardiac repolarization to the same relative extent.

Lactic acid

Several factors are responsible for the tremendous amount of variation seen in the rate of lactic acid removal by iguanas at any one temperature. One relates to the 
fact that the final concentration of blood lactate reached for a given individual at a particular temperature could not be controlled experimentally. Others include the patterns of activity during recovery and variations in heart rate and peripheral blood flow.

The increased rate of removal of lactic acid with temperature is probably due to two sets of factors working together. One involves the increase in rate due to the temperature effects on the enzymatic machinery itself. If none of the enzymes are undergoing thermal denaturation, one would conventionally expect to see the rate approximately double for each $10^{\circ} \mathrm{C}$ rise in temperature. Since iguanas have a preferred temperature of $36.2^{\circ} \mathrm{C}$, a voluntary tolerance of $40^{\circ} \mathrm{C}$ and an upper lethal temperature of $47^{\circ} \mathrm{C}$ (McGinnis \& Brown, 1966), it is unlikely that major enzymatic denaturation would be occurring in the range of temperature studied. This idea is further supported by the data of Licht (1964) on the thermostability of some selected lizard enzymes. All those investigated were quite stable to $40^{\circ} \mathrm{C}$. Thus one would expect the rate at which oxygen debts are removed to increase as the temperature increased all the way to $40^{\circ} \mathrm{C}$. However, this did not occur. Consequently, a second set of factors must be invoked. This might well concern the oxygen available for the elimination of the debt. As can be seen in Fig. 4, the early stages of the recovery period are most critical as regards the reduction of the levels of lactate in the animal. In this stage, oxygen consumption is maximal, and the amount of oxygen available is, therefore, heavily dependent on the metabolic scope. As we have noted above, this peaks at about $32^{\circ} \mathrm{C}$, and declines steadily thereafter. The value at $40^{\circ} \mathrm{C}$ is 83 per cent that at $35^{\circ} \mathrm{C}$. Thus the drop in rate at high temperatures may be due to a decreased metabolic scope. The metabolic scope at $40^{\circ} \mathrm{C}$ is the same as that at $27^{\circ} \mathrm{C}$. It, therefore, appears significant that the rate of removal of lactate at $40^{\circ} \mathrm{C}$ is just slightly higher than that at $25^{\circ} \mathrm{C}$.

The measurements of lactate levels in tissues other than blood lead to some rather interesting questions and suggestions. The very high levels seen in the muscles as compared with the blood indicate that appreciable time is required for the lactic acid to diffuse from the tissues into the blood. This was also indicated previously by the fact that peak levels of blood lactate did not appear until 10 $35 \mathrm{~min}$ after the termination of activity in five of the tests. The time required for for the appearance of lactate in the blood generally bore an inverse relation to body temperature. This could be due to circulatory adjustments or possible impairment of lactate transport across cell membranes. The low levels of lactate found in the liver of iguanas suggest that this organ is rapidly converting the lactic acid of the blood stream back into glucose and other carbohydrate intermediates, a function long ascribed to this organ in mammals.

\section{The roles of aerobic and anaerobic metabolism during activity}

With the data obtained in this study, it is now possible to estimate the relative roles of aerobic and anaerobic metabolism during a burst of maximum activity by an iguana. The longest violent struggle by an iguana on the jig was $5 \mathrm{~min}$. If one constructs a metabolic balance sheet for a $1000-\mathrm{g}$ iguana struggling at $35^{\circ} \mathrm{C}$ for this 
length of time, it can be determined that the percentage contribution of anaerobic metabolism is at least 77 per cent (see Moberly, 1966, for a detailed balance sheet).

Iguanas, therefore, appear to depend very heavily indeed on anaerobic metabolism for short vigorous bursts of activity. It should be noted that the above estimate is a conservative one. The values used for oxygen consumption are maximal for the entire period of activity specified, so the estimate of aerobic metabolism will be slightly high. The values used for lactic acid will be low, for they are taken for animals with values of only $84 \mathrm{mg}$ per cent lactate in the blood. Blood levels of lactate can and do go much higher, and peak levels can be reached in less than $5 \mathrm{~min}$. The values for muscle probably also can go much higher, as they can reach levels in excess of $500 \mathrm{mg}$ per cent in fish (Black et al., 1961). Furthermore, the lactic acid being produced by the muscles during activity is being removed from the blood by the liver at the same time due to gluconeogenesis, and thus the peak levels seen give a low estimate of the total amount produced.

\section{Blood glucose}

The general stability of the level of blood glucose during and immediately afte exercise by iguanas suggests that no significant usage of this substance occurs during the burst of activity, or that a very good system for maintaining the concentration of blood glucose during activity is present. The lack of utilization could result from the sudden appearance of a tremendous excess of oxidizable substrate directly available within the muscle, in the form of lactate. Utilization of carbohydrate reserves probably becomes necessary only in prolonged exercise. During recovery from the large amounts of lactic acid built up by the burst of activity, levels of blood glucose might be expected to rise as glucose was synthesized from lactate by the liver and returned to the muscles for resynthesis into muscle glycogen. A slight indication of this was seen in some animals.

\section{Carbohydrate reserves for activity}

From the values for the tissue composition of an iguana (Moberly, 1966) and the values obtained from the glycogen determinations, it is possible to calculate the amount of glycogen in the muscles and liver of a representative lizard of known weight, if it is assumed that the glycogen is uniformly distributed in these tissues. Such a calculation indicates that it is possible to account for all of the lactic acid produced from muscle glycogen alone, without the necessity of drawing on liver stores or blood glucose (Moberly, 1966).

Further strong evidence to support this view was obtained using histochemical techniques. It was shown that glycogen was almost completely eliminated in the muscle after exercise, but levels seemed to be little altered in the liver tissue (Moberly, 1966).

\section{SUMMARY AND CONCLUSIONS}

Standard metabolic rate in the iguana increases as an exponential function of increasing temperature. However, it has not been observed to exceed $0.25 \mathrm{ml}$ 
$\mathrm{O}_{2} / \mathrm{g}$ per $\mathrm{hr}$, a value less than half the basal rate of a mammal of comparable size. Even the highest rates observed in the iguanas are below the mammalian level. Thus it is immediately obvious that this lizard, with its low metabolism and lack of fur or feathers, must depend on insolation and conduction from the substrate to raise its body temperature to levels well in excess of the environment. The animals seen in Colombia spent most of the day basking in the sun.

When iguanas become active, the metabolic scope (the absolute difference between standard and maximum oxygen consumption) is greatest at about $32^{\circ} \mathrm{C}$, where it amounts to four times the oxygen consumption of the animals at rest. This is overshadowed by the capacities of some homeotherms, which may increase aerobic metabolism up to twenty times during activity (Karpovich, 1965), and by some insects, which may increase metabolism 50-200 times (Prosser \& Brown, 1961). Heart rate of iguanas is approximately doubled during activity. Standard and maximum heart rate, as well as the absolute difference between them, continues to rise as the lizards become heated to $42^{\circ} \mathrm{C}$, the highest temperature measured. The oxygen consumption increases relatively more than heart rate during activity, and this means that the oxygen pulse has to increase. This in turn must involve an increase in arteriovenous (A-V) difference in oxygen carried in the blood and/or stroke volume. Tucker (1966) has shown that stroke volume of iguanas can either increase or decrease during activity and that the $\mathrm{A}-\mathrm{V}$ difference can reach 8.5 vol. per cent, representing a nearly total reduction of the blood. The cardiovascular system of the iguana is thus able to meet the increased demands for oxygen during activity in a restricted manner, and further reflects the rather limited ability of this animal to increase aerobic metabolism.

The relatively small capability of iguanas for increasing aerobic metabolism leads one to expect that these lizards must primarily support vigorous activity by anaerobic means. Measurements proved this to be the case, approximately threefourths of the energy required during a vigorous 5 -min burst of activity at $35^{\circ} \mathrm{C}$ being accounted for through anaerobic pathways. Sufficient glycogen reserves are found in the muscles themselves to supply the required compounds for anaerobic oxidation. These are quickly and completely mobilized during activity (Moberly, 1966). Liver stores of glycogen and blood glucose seem to play little role in supporting activity. All these findings indicate that iguanas must be very sedentary creatures. It would appear that when they are faced with possible predation their response would have to be the attainment of a place of safety in as short a time as possible, accomplishing this with a quick burst of anaerobic activity. This proved to be the case, with iguanas in the field diving into water which was always within $50 \mathrm{ft}$ (horizontal distance) of their location in trees.

The rapidity with which an oxygen debt can be removed after activity is also temperature-dependent, and seems to correlate fairly well with the metabolic scope. The maximum rate of removal occurred at about $35^{\circ} \mathrm{C}$. This rate is particularly important to an animal that relies so heavily on anaerobic metabolism. Thus from the standpoint of aerobic and anaerobic metabolism, a preferred temperature in the range $32-35^{\circ} \mathrm{C}$ would be most advantageous for an iguana. It actually 
appears to be $36.2^{\circ} \mathrm{C}$ in the field when adequate insolation is available. However, these lizards apparently must spend much of the year at temperatures of $33-34^{\circ} \mathrm{C}$ due to inadequate insolation during the rainy season. In view of the metabolic data, the animals are obviously not penalized by this. The reason for the higher preferred temperature remains unexplained.

Thus we see that the physiological correlates of activity permit only a very restricted mode of life in the iguana. Metabolic measurements can obviously never take the place of direct field observations, but when coupled with them provide a basis for interpreting what is seen.

It has become apparent from this study that the iguana is an animal which has taken maximum advantage of a low metabolism and lethargic way of life, relying on large bursts of effort for extremely short periods in the course of its existence. This dependence on anaerobic metabolism has several advantages for an animal with such a mode of life. It is undoubtedly less expensive energetically to maintain the relatively inert carbohydrate reserves and few enzymes necessary for anaerobic energy production than it is to maintain the structurally and enzymatically complex apparatus required for high rates of aerobic energy production. In addition, it adds a measure of homeostasis to the iguana's system. The amount of anaerobic metabolism that can be undertaken seems to be temperature-independent. Since most of the energy for activity comes through this pathway, the effects of temperature on aerobic metabolism are not of primary importance during the actual period of activity itself. However, they become important during recovery.

The responses of iguanas to unrestrained activity are of considerable interest. For instance, it might be profitable to ask if the great capacity for anaerobic metabolism might be put to some further advantage. Also of interest is the question of exactly how much strictly aerobic activity the animals are capable of performing. Both of these questions are examined in the following paper (Moberly, 1968).

Acknowledgements-The author wishes to thank Dr. William Dawson for critical help during all stages of the work. Much aid was also rendered by Dr. Donald Tinkle, Billie Frye, David Shappirio and Claude Hibbard. Successful completion of the fielded work in Colombia would not have been possible without the co-operation of Drs. Carlos Lehmann, Federico Medem, Luis and Ignacio Borrero. Señores Marco Galarza and Carlos Velasquez provided invaluable field assistance.

\section{REFERENCES}

Bartholomew G. A. \& Tucker V. A. (1963) Control of changes in body temperature, metabolism and circulation by the agamid lizard, Amphibolurus barbatus. Physiol. Zool. 36, 199-218.

BARTHOLOMEW G. A. \& TuCKRR V. A. (1964) Size, body temperature, thermal conductance, oxygen consumption, and heart rate in Australian varanid lizards. Physiol. Zool. 37, $341-354$.

Bartholomew G. A., Tucker V. A. \& Lex A. K. (1965) Oxygen consumption, thermal conductance, and heart rate in the Australian skink, Tiliqua scincoides. Copeia 1965, 169-173. 
Black E. C. (1957) Alterations in the blood level of lactic acid in certain salmonid fishes following muscular activity-1. Kamloops trout Salmo gairdneri. F. Fish. Res. Bd Can. 14, 117-134.

Black E. C., Robertson A. C. \& PARKER R. R. (1961) Some aspects of carbohydrate metabolism in fish. In Comparative Physiology of Carbohydrate Metabolism in Heterothermic animals (Edited by MarTIN A. W.), pp. 89-124. Univ. of Washington Press, Seattle.

BogkRT C. M. (1949) Thermoregulation in reptiles, a factor in evolution. Evolution 3, 195-211.

DAWE A. R. \& MoRRISON P. R. (1953) ONR progress report from the University of Wisconsin (N4 ONR 28506), 30 June 1953.

Dawson W. R. (1960) Physiological responses to temperature in the lizard Eumeces obsoletus. Physiol.Zool. 31, 87-103.

Dawson W. R. (1967) Interspecific variation in physiological responses of lizards to temperature. In Lizard Ecology: $A$ Symposium (Edited by MiLSTEAD W. W.), pp. 230-257. Univ. of Missouri Press, Columbia.

Dawson W. R. \& Templeton J. R. (1963) Physiological responses to temperature in the lizard Crotaphytus collaris. Physiol.Zool. 36, 219-236.

Fry F. E. J. (1947) Effects of the Environment on Animal Activity. Publs Ontario Fish. Res. Lab. No. 68.

FRY F. E. J. (1957) The aquatic respiration of fish. In The physiology of Fishes (Edited by Brown M. E.), pp. 1-63. Academic Press, New York.

HiRTH H. F. (1963) Some aspects of the natural history of Iguana iguana on a tropical strand. Ecology 44, 613-615.

HugGetT A. St. G. \& Nixon D. A. (1957) Enzymatic determination of blood glucose. Biochem. F. 66, 12p.

Karpovich P. V. (1965) Physiology of Muscular Activity (6th edn.) Saunders, Philadelphia.

KROGH A. (1914) The quantitative relation between temperature and standard metabolism in animals. Int. Z. phys.-chem. Biol. 1, 491-508.

Licht P. (1964) The thermal dependence of myosin-adenosine-triphosphatase and alkaline phosphatase. Comp. Biochem. Physiol. 12, 331-340.

Lichr P. (1965) Effects of temperature on heart rates of lizards during rest and activity. Physiol.Zool. 38, 129-137.

LofTiN H. \& TYson E. L. (1965) Iguanas as carrion eaters. Copeia 1966, 515.

McGinnis S. M. \& Brown C. W. (1966) Thermal behavior of the green iguana, Iguana iguana. Herpetologica 22, 189-199.

MoberLy W. R. (1966) The physiological correlates of activity in the common iguana, Iguana iguana. Ph.D. Thesis, Univ. of Michigan, Ann Arbor.

MOBERLY W. R. (1968) The metabolic responses of the common iguana, Iguana iguana, to walking and diving. Comp. Biochem. Physiol. 27, 21-32.

Prosser C. L. \& Brown F. A. (1961) Comparative Animal Physiology (2nd edn.) Saunders, Philadelphia.

Scholz R., Schmitz H., Bucher Th. \& Lampen J. O. (1959) Über die von nystatin auf Bäckerhefe. Biochem.Z. 331, 71-86.

Seifter S., Dayton S., Novic B. \& Muntwyler E. (1950) The estimation of glycogen with the anthrone reagent. Archs Biochem. 25, 191-200.

Swanson P. L. (1950) The iguana Iguana iguana iguana (L.). Herpetologica 6, 187-193.

TAYLOR E. H. (1956) A review of the lizards of Costa Rica. Univ. Kansas Sci. Bull. 38, 1-322.

TUCKER V. A. (1966) Oxygen transport by the circulatory system of the green iguana (Iguana iguana) at different body temperatures. F. exp. Biol. 44, 77-92. 